Check for updates

Cite this: J. Mater. Chem. B, 2018, 6, 289

Received 8th March 2017, Accepted 3rd December 2017

DOI: $10.1039 / c 7$ tb00646b

rsc.li/materials-b

\section{Development of tailored SPION-PNIPAM nanoparticles by ATRP for dually responsive doxorubicin delivery and MR imaging $\dagger$}

\author{
Yasemin Yar, ${ }^{a}$ Rouhollah Khodadust, (D) ${ }^{b}$ Yunus Akkoc, (D) ${ }^{c}$ Mustafa Utkur, ${ }^{e}$ \\ Emine Ulku Saritas, (D) ${ }^{e}$ Devrim Gozuacik (D) ${ }^{\text {cd }}$ and Havva Yagci Acar (D) *abdf
}

\begin{abstract}
Biocompatible, colloidally stable and ultra-small $\mathrm{Fe}_{3} \mathrm{O}_{4}$ nanoparticles (SPIONs) coated with poly(N-isopropylacrylamide) (PNIPAM) were synthesized via surface-initiated ATRP (atom transfer radical polymerization) to prevent excessive aggregation of magnetic cores and interparticle crosslinking, and to provide control over polymer content. These SPION-PNIPAM nanoparticles (NPS) have a hydrodynamic size between 8 and $60 \mathrm{~nm}$ depending on the PNIPAM content, and hence are ultrasmall in size and have an LCST around $38^{\circ} \mathrm{C}$. They had a high drug-loading capacity reaching 9.6 wt\% doxorubicin in the final composition. The Dox release studies revealed $\mathrm{pH}$ and temperature-dependent release, which was not reported for PNIPAM before. Release of Dox under physiological conditions was below $20 \%$, but around $90 \%$ at $42{ }^{\circ} \mathrm{C}$ and $\mathrm{pH} 5$. This dually responsive nature is very advantageous to increase the drug efficacy and reduce side-effects, simultaneously. The cytocompatability of the SPION-PNIPAM NPs and the influence of Dox delivery to cells were investigated via in vitro cell viability, apoptosis, DNA-damage and confocal microscopy studies. The NPs were shown to be highly cytocompatible and induce significant cell death due to Dox when loaded with the drug. Besides, it was seen that the polymeric content can be used as an additional factor in tuning the release kinetics. Lastly, these nanoparticles reduced the signal intensity significantly in the T2 mode, acting as a potential SPION-based contrast agent. Overall, here, we demonstrate the design of small, smart theranostic nanoparticles with high drug-loading capacity and $\mathrm{pH}$-dependent temperature-sensitive release characteristics with the ability to generate contrast in MRI.
\end{abstract}

\section{Introduction}

Superparamagnetic iron oxide nanoparticles (SPIONs) are biocompatible nanoparticles (NPs) that are widely investigated in the fields of biotechnology and medicine. ${ }^{1-3}$ These nanoparticles can

\footnotetext{
${ }^{a}$ Koc University, Graduate School of Materials Science and Engineering, Rumelifeneri Yolu, Sariyer, Istanbul, Turkey

${ }^{b}$ Koc University, Department of Chemistry, Rumelifeneri Yolu, Sariyer, Istanbul, Turkey

${ }^{c}$ Sabanci University, Faculty of Engineering and Natural Sciences, Molecular Biology, Genetics and Bioengineering Programs, Istanbul, Turkey

${ }^{d}$ Sabanci University, Center of Excellence for Functional Surfaces and Interfaces for NanoDiagnostics (EFSUN), Istanbul, Turkey

${ }^{e}$ Department of Electrical \& Electronics Engineering and National Magnetic Resonance Research Center (UMRAM), Bilkent University, Ankara, Turkey

${ }^{f}$ Koc University, Surface Science and Technology Center (KUYTAM), Rumelifeneri Yolu, Sariyer, Istanbul, Turkey. E-mail: fyagci@ku.edu.tr

$\dagger$ Electronic supplementary information (ESI) available: Crystal size analysis (Fig. S1), Dox release from SPION-PNIPAM02 at different $\mathrm{pH}$ and temperatures (Fig. S2), confocal laser microscopy images of HeLa cells treated only with Dox (Fig. S3), and the supporting video indicating the internalization of Dox-loaded nanoparticles by HeLa cells. See DOI: 10.1039/c7tb00646b
}

be used as diagnostic and therapeutic agents. ${ }^{4}$ They change the relaxation rate of protons in a magnetic field and hence are used as MRI contrast agents. ${ }^{5}$ They can be loaded with drugs or genes and are therefore utilized as drug delivery vehicles. ${ }^{6-8}$ They can be dragged by an external magnetic field and exploited for sitespecific delivery, as well. ${ }^{5}$ In addition, in an alternating magnetic field, SPIONs can lead to a local temperature increase and cause hyperthermia. ${ }^{7,9}$ Of course, the combination of these properties in a single SPION formulation is invaluable in terms of simplicity of formulation and material economy, especially when in vivo applications are considered. Hence, SPIONs are considered multifunctional "theranostic" nanoparticles.

There is tremendous effort in utilizing nanoparticles for the delivery of chemotherapy drugs such as doxorubicin (Dox). Systemic administration of these drugs results in severe side effects including cardiotoxicity in the case of Dox which poses lifetime dose limits and treatment failures. Loading such drugs onto SPIONs may provide multiple advantages including longer circulation of the drug in the blood, enhanced delivery into tumors via EPR effects and the possibility of targeted delivery (molecular or magnetic) to tumor sites allowing higher local 
concentrations, increasing efficacy and reducing systemic side effects. Of course, the MRI active nature of SPIONs is a major advantage providing a means to track nanoparticles and to monitor the outcome of the therapies. ${ }^{7}$

Critical factors for SPION-based drug delivery vehicles include overall size of the NPs and character of the coating. These parameters influence escape from the reticulo-endothelial system (RES), stability, overall biocompatibility and drug binding and release ability. ${ }^{10}$ Polymers are widely used as coating materials which can also provide sensitivity to $\mathrm{pH}$, temperature, ionic strength, electric or magnetic fields, light, and chemical or biological stimuli. ${ }^{11-14}$

Poly( $N$-isopropylacrylamide) (PNIPAM) is one of the most studied polymers for biomedical applications. ${ }^{15-18}$ It is biocompatible and temperature-responsive with a lower critical solution temperature (LCST) around $32{ }^{\circ} \mathrm{C}$, which is close to the body temperature $\left(37^{\circ} \mathrm{C}\right) .{ }^{16}$ The LCST of the polymer can be tuned by altering the molecular weight or architecture ${ }^{11,12}$ and copolymerization. ${ }^{19,20}$ In addition, due to its amphiphilic nature, large inner volume, adjustable permeability, and thermo-responsive nature, PNIPAM is very attractive for drugencapsulation and controlled release. ${ }^{21,22}$ There is great interest in stimuli responsive release of drugs since this can be exploited to achieve a therapeutic effect only at targeted sites.

Combination of the thermo-responsive drug delivery potential of PNIPAM with the magnetic targeting and hyperthermia potential of SPIONs may provide increased antineoplastic drug accumulation in tumors and enhanced antitumor cytotoxicity of the drug. Several studies have demonstrated that combination therapies will be far more effective than either hyperthermia or chemotherapy alone, and the cytotoxic activity of many anticancer agents is maximized with mild hyperthermia $\left(40.5-43{ }^{\circ} \mathrm{C}\right) .{ }^{23,24}$

There are a few studies in which SPIONs and PNIPAM were combined. $^{4,25,26}$ These composite structures were prepared via free radical polymerization of NIPAM and co-monomers in the presence of SPIONs resulting in physical encapsulation of the nanoparticles. ${ }^{27,28}$ Sometimes, monomer-tethered SPIONs were used in order to provide chemical attachment sites. ${ }^{4,25,26}$ Such particles have aggregated SPION cores and overall sizes of around $250 \mathrm{~nm}$ or larger at room temperature. Particle sizes larger than $150 \mathrm{~nm}$ are usually problematic in vivo since larger particles have very short blood circulation times and they quickly end up in the liver. ${ }^{29,30}$ In the case of Dox-loaded SPIONs combined with PNIPAM, there are major problems that need to be addressed: large overall size of the nanoparticles, low drug loading and ineffective drug release. ${ }^{4,26,27,29}$

Here, we describe the development of biocompatible, multifunctional smart theranostic nanoparticles composed of SPIONs and PNIPAM via a "grafting from" technique utilizing ATRP, achieving controlled PNIPAM thickness with an overall nanoparticle size below $60 \mathrm{~nm}$. The overall design strategy is summarized in Scheme 1. This approach utilizes initiator-coated SPIONs via ligand exchange of fatty acid-coated magnetic cores to prevent the aggregation of the magnetic cores at the early stage. Utilization of ATRP prevents interparticle crosslinking and provides a dense polymer coating with controlled polymer

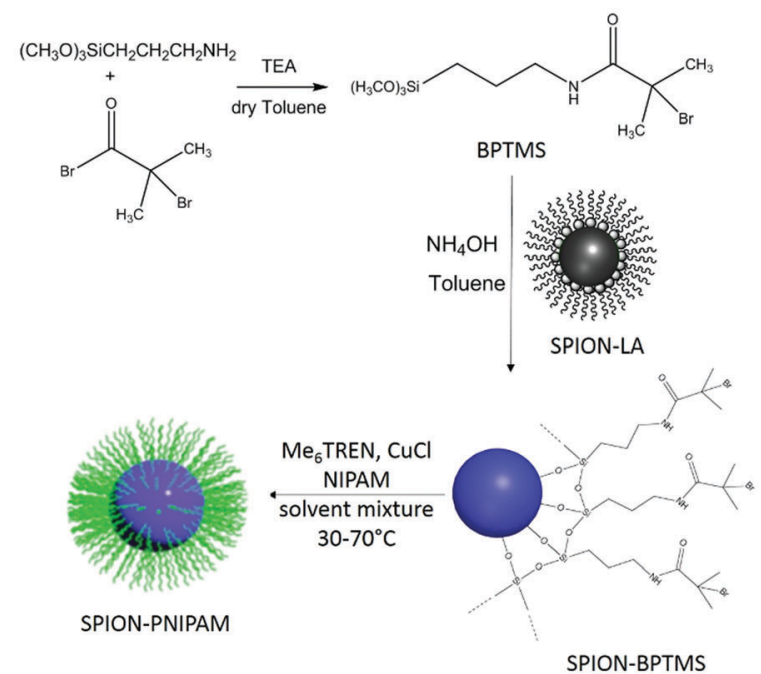

Scheme 1 Schematic representation of step-by-step synthesis of PNIPAM-coated magnetic nanoparticles (SPION-PNIPAM).

molecular weight, and hence polymer content. This would be important to control the stability and hydrodynamic size of the overall nanoparticles, drug-loading/unloading capacity and kinetics, and also biodistribution in the future in vivo applications of such nanoparticles. There are only a couple of examples of such polymerizations of NIPAM, due to the difficulty of polymerizing acrylamides by ATRP. ${ }^{31-34}$ The advantage of using a thermo-responsive polymer is to trigger drug release above the body-temperature and at the tumor site, so that the drug will not be released while in the blood circulation and it will not reach high concentrations at non-targeted sites. We designed nanoparticles with different PNIPAM content. PNIPAM was grown from the SPION surface long enough to provide colloidal stability. The thermosresponsive nature of the SPION-PNIPAM nanoparticles was demonstrated. Drug-loading/unloading capacities were analyzed using Dox as a model drug. Influence of the temperature, $\mathrm{pH}$ and PNIPAM content on drug release was studied in detail in a time-dependent manner. PBS buffer at $\mathrm{pH} 7.4$ and phosphate buffer at $\mathrm{pH} 5$ were used to mimic the $\mathrm{pH}$ of the blood stream and cell endosome, respectively. For temperature-dependent release, 22,37 and $42{ }^{\circ} \mathrm{C}$ were studied to mimic moderate room storage, physiological condition and possible hyperthermia temperatures, respectively. The toxicity of the SPION-PNIPAM and therapeutic effects of the Dox-loaded nanoparticles were tested in vitro using HeLa (epithelial cervix carcinoma) cells in a time and dose-dependent manner. Cellular uptake, cell proliferation, DNA damage and apoptosis studies were also performed. Nanoparticle internalization, intracellular localization, kinetics of Dox release from the nanoparticles and nuclear localization were also studied using HeLa cells demonstrating the influence of temperature and PNIPAM content on these kinetics. In addition, we evaluated the potential of these particles as MRI contrast agents which would allow tracking of the destiny of particles in vitro and in vivo and monitoring the outcome of the therapy, in future studies. 


\section{Experimental section}

\subsection{Materials}

All materials were used as received unless otherwise noted. $N$-Isopropylacrylamide (NIPAM) was recrystallized twice from hexane. $\mathrm{CuCl}$ (99.99\%) was purchased from Acros Organics. Iron(III) chloride hexahydrate $\left(\mathrm{FeCl}_{3} \cdot 6 \mathrm{H}_{2} \mathrm{O}\right)$, iron(II) chloride tetrahydrate $\left(\mathrm{FeCl}_{2} \cdot 4 \mathrm{H}_{2} \mathrm{O}\right), \alpha$-bromoisobutyryl bromide, tris-2aminoethyl amine (TREN), tryphan blue, DAPI dihydrochloride, dimethyl sulfoxide (DMSO), bradford reagent, RIPA supplied with protease inhibitior cocktail, $1 \mathrm{mM}$ phenylmethylsulfonyl fluoride, and lauric acid (LA) were purchased from SigmaAldrich. 3-Aminopropyl tri-methoxysilane (APTMS) was purchased from Gelest, Inc (Morrisvile, PA). Ammonium hydroxide $\left(\mathrm{NH}_{4} \mathrm{OH}\right.$, $26 \%$ ), dimethylformamide (DMF), triethylamine, ethyl acetate (EtAc), formic acid, chloroform, formaldehyde (37\%), sodium dihydrogen phosphate dehydrate $\left(\mathrm{NaH}_{2} \mathrm{PO}_{4} \cdot \mathrm{H}_{2} \mathrm{O}\right)$, and toluene were purchased from Merck. Phosphate buffer saline (PBS) was purchased from Biotechnology. Thiazolyl blue tetrazolium bromide (MTT assay kit) was purchased from Applichem. Dox-HCl was supplied by SABA Turkey. DMEM, fetal bovine serum, antibiotics (penicillin/streptomycin) and L-glutamine were purchased from Biological Industries. Nitrocellulose membranes and Anti-gamma-H2AX were purchased from Millipore. Anti-CC9, anti-CC7 and anti-P53 abs were purchased from Santa Cruz. Anti- $\beta$-ACTIN antibody as a loading control was purchased from Sigma. Anti-mouse and anti-rabbit secondary antibodies were purchased from Jackson Laboratories.

\subsection{Lauric acid-coated superparamagnetic iron oxide $\left(\mathrm{Fe}_{3} \mathrm{O}_{4}\right.$-LA) nanoparticles}

$\mathrm{FeCl}_{3} \cdot 6 \mathrm{H}_{2} \mathrm{O}(2.365 \mathrm{~g}, 8.75 \mathrm{mmol}), \mathrm{FeCl}_{2} \cdot 4 \mathrm{H}_{2} \mathrm{O}(0.870 \mathrm{~g}, 4.37 \mathrm{mmol})$ and $1.64 \mathrm{~mL}$ of LA were dissolved in $46 \mathrm{~mL}$ of deoxygenated water, purged with nitrogen and treated with $\mathrm{NH}_{4} \mathrm{OH}(12.06 \mathrm{~mL}, 26 \%)$ at $85{ }^{\circ} \mathrm{C}$ in an oil bath under an inert atmosphere. After 30 of min reaction, the colloidal solution was cooled to room temperature, any precipitate was removed by magnetic decantation and the colloidal particles were washed with fresh DI water using the Amicon Ultra centrifugal filter (10 kDa cutoff).

$10 \mathrm{~mL}$ of this aqueous colloidal solution were shaken vigorously with $20 \mathrm{~mL}$ of toluene and $3 \mathrm{~mL}$ of isopropyl alcohol for $15 \mathrm{~min}$, and the organic phase, containing the LA monolayercoated SPIONs, was separated. This extraction procedure transfers all SPIONs into the organic phase.

\subsection{Synthesis of 2-bromopropionamidepropyl tri- methoxysilane (BPTMS)}

3-Aminopropyl trimethoxysilane $(3.6 \mathrm{~mL})$ and triethylamine $(4 \mathrm{~mL})$ were added into $200 \mathrm{~mL}$ anhydrous toluene and the solution was cooled in an ice bath under nitrogen. $\alpha$-Bromoisobutyryl bromide $(3 \mathrm{~mL})$ was slowly added to this cold solution and then it was left to equilibrate to room temperature. After an overnight reaction, the triethylamonium bromide salt was removed by filtration. The product was obtained as a yellow-brownish viscous liquid in 96\% yield, after the evaporation of toluene under vacuum.

\subsection{Synthesis of tris[2-(dimethylamino)ethyl] amine (Me ${ }_{6}$ TREN)}

An aqueous solution of TREN ( $10 \mathrm{~g}$ in $5 \mathrm{~mL}$ water) was added to a mixture of formaldehyde $(29 \mathrm{~mL}, 90 \%)$ and formic acid (35 mL) in an ice bath and stirred overnight. All the volatiles were removed under reduced pressure, yielding a viscous residue. This was treated with a saturated $\mathrm{NaOH}$ solution until the $\mathrm{pH}$ of the solution raised above 10 and then it was extracted with dichloromethane. The product was obtained after the removal of the solvent under vacuum.

\subsection{Synthesis of ATRP initiator-functionalized nanoparticles (BPTMS-SPIONs)}

$30 \mathrm{~mL}$ of LA monolayer-coated SPIONs and $1.6970 \mathrm{~g}$ of BPTMS were mixed in a three-neck round-bottomed flask under nitrogen. $1 \mathrm{~mL}$ of $\mathrm{NH}_{4} \mathrm{OH}$ was injected and stirred at room temperature overnight. BPTMS-bound SPIONs were precipitated into hexane, washed with toluene twice and re-suspended in DMF.

\subsection{Surface-initiated ATRP of NIPAM from BPTMS-SPIONs (SPION-PNIPAM)}

In a typical polymerization, $\mathrm{CuCl}(0.2434 \mathrm{~g})$ was dissolved in $4 \mathrm{~mL}$ DMF under an inert atmosphere and then added to the monomer solution consisting of NIPAM (4.0937 g), $15 \mathrm{~mL}$ organic solvent (EtAc or THF) and $20 \mathrm{~mL}$ water. Deoxygenated $\mathrm{Me}_{6}$ TREN $(83 \mu \mathrm{L})$ was injected into the reaction vessel. Finally, $0.5 \mathrm{~mL}$ of BPTMS-SPIONs was added. Polymerizations were performed at $70{ }^{\circ} \mathrm{C}$. The viscosity of the polymer solution increased with time. SPION-PNIPAM was cleaned by dialysis (3.5 kDa molecular weight cut-off, CelluseSep T1 Regenerated cellulose tubular membrane) and lyophilized in order to obtain fine powders. Specifics of the reactions are given in Table 1.

\subsection{Dox loading to SPION-PNIPAM}

Drug loading of the NPs was carried out at a drug/NP ratio of $1: 10$ (wt/wt) both in de-ionized water (DIW) and PBS buffer at a $50 \mathrm{~mL}$ scale. First, NPs were diluted in the DIW or PBS and stirred for $30 \mathrm{~min}$ to ensure a homogenous solution. Then, Dox solution (DIW or PBS) was added to the NP suspensions and stirred at $500 \mathrm{rpm}$ for $15 \mathrm{~h}$ in the dark. Unbound Dox was

Table 1 Polymerization conditions of NIPAM from SPION-BPTMS and polymer properties

\begin{tabular}{|c|c|c|c|c|c|c|c|}
\hline Sample & {$[\mathrm{In}] /[\mathrm{CuCl}] /[\mathrm{Me} 6 \mathrm{TREN}] /[\mathrm{M}]$} & Solvent (v/v) & Conv. $^{a}(\%)$ & $M_{\mathrm{n}}^{b}(\mathrm{kDa})$ & $M_{\mathrm{n}}^{c}(\mathrm{kDa})$ & $M_{\mathrm{w}}{ }^{c}(\mathrm{kDa})$ & $\mathrm{PDI}^{d}$ \\
\hline${\text { PNIPAM } 01^{e}}^{e}$ & $1 / 1 / 1 / 1000$ & $6 \mathrm{H}_{2} \mathrm{O} / 12 \mathrm{DMF} / 10 \mathrm{THF}$ & 23 & 25.9 & 20.4 & 31.5 & 1.54 \\
\hline PNIPAM0 $2^{f}$ & $1 / 30 / 50 / 2500$ & $21 \mathrm{H}_{2} \mathrm{O} / 4 \mathrm{DMF} / 15 \mathrm{EtAc}$ & 62 & 174.4 & - & - & - \\
\hline
\end{tabular}

${ }^{a}$ Measured gravimetrically. ${ }^{b}$ Theroretical $M_{\mathrm{n}} \cdot{ }^{c}$ Measured by GPC. ${ }^{d} M_{\mathrm{w}} / M_{\mathrm{n}} \cdot{ }^{e}$ Reaction at $30{ }^{\circ} \mathrm{C} .{ }^{f}$ Reaction at $70{ }^{\circ} \mathrm{C}$. 
removed by the dynamic dialysis technique. Briefly, Dox-loaded NPs were sealed in a dialysis bag (MWCO 3500 dialysis membrane, CelluseSep T1 Regenerated Cellulose Tubular Membrane) and incubated in 1 L DIW or PBS (pH 7.4) at room temperature in a shaker at $300 \mathrm{rpm}$. Dox-loading efficiency and Dox-loading content were quantified by measuring the photoluminescence (PL) intensity of the solutions $\left(\lambda_{\text {exc }}=470 \mathrm{~nm}\right.$; $\lambda_{\mathrm{em}}=585 \mathrm{~nm}$ ) on a Horiba Jobin Yvon-Fluoromax-3 spectrophotometer by using eqn (1) and (2).

$$
\begin{aligned}
& \text { Drug loading efficieny }(\%) \\
& =\frac{\text { total } \mu \mathrm{g} \text { of drug added }-\mu \mathrm{g} \text { of unloaded drug }}{\text { total } \mu \mathrm{g} \text { of drug added }} \times 100
\end{aligned}
$$

Drug loading content $(\%)=\frac{\mu \mathrm{g} \text { of the drug in nanoparticles }}{\text { total } \mu \mathrm{g} \text { of the nanoparticles }} \times 100$

\subsection{Dox release from SPION-PNIPAM}

In vitro release of Dox from SPION-PNIPAM was determined by the dynamic dialysis technique. Briefly, $50 \mathrm{~mL}$ of SPIONPNIPAM-Dox was sealed in a dialysis bag (MWCO $3.5 \mathrm{kDa}$ ), and incubated in $1 \mathrm{~L}$ PBS ( $\mathrm{pH}$ 7.4) or phosphate ( $\mathrm{pH} 5)$ buffers in a shaker at $300 \mathrm{rpm}$ at 37 and $42{ }^{\circ} \mathrm{C}$, separately, up to 48 hours. At different time intervals, $2 \mathrm{~mL}$ aliquots were taken out to measure the released Dox amount and $2 \mathrm{~mL}$ buffer was added to the main solution. The amount of Dox released was quantified by the emission intensity of Dox measured by spectrofluorometer $\left(\lambda_{\mathrm{exc}}=470 \mathrm{~nm} ; \lambda_{\mathrm{em}}=585 \mathrm{~nm}\right)$.

\subsection{Cell culture}

The HeLa (Human cervical carcinoma) cell line was regularly cultured in Dulbecco's modified Eagle medium (DMEM), supplemented with $10 \%(\mathrm{v} / \mathrm{v})$ fetal bovine serum (FBS) and $2 \mathrm{mM}$ L-glutamine. The cells were maintained in a $5 \% \mathrm{CO}_{2}$ humidified incubator at $37{ }^{\circ} \mathrm{C}$. For the MTT assay, the cells were grown in 96-well culture plates at $37{ }^{\circ} \mathrm{C}$ and under $5 \% \mathrm{CO}_{2}$ in a DMEM medium supplemented with $10 \% \mathrm{FBS}$ and antibiotics. 48 and 72 hours after nanoparticle treatment, $5 \mathrm{mg} \mathrm{mL}^{-1}$ MTT reagent was added into each well. $3.5 \mathrm{~h}$ later, the medium was replaced with $150 \mu \mathrm{L}$ ethanol/DMSO $(1: 1 \mathrm{v} / \mathrm{v})$. The plates were agitated for $15 \mathrm{~min}$ at room temperature to dissolve the formazan. Cell viability was quantified spectrophotometrically using an ELISA reader at $590 \mathrm{~nm}$ with a $620 \mathrm{~nm}$ filter. Experiments were performed in triplicate and the data are shown as the mean $\pm \mathrm{SD}(n=3)$.

\subsection{DNA damage and apoptosis assays}

Cell death (apoptosis) was documented as caspase cleavage analysis on immunoblots as previously described. ${ }^{35,36}$ The cells were lysed in RIPA buffer (50 mM Tris pH 7.4, $150 \mathrm{mM} \mathrm{NaCl}$, $1 \% \mathrm{NP}_{4} \mathrm{O}, 0.25 \%$ Na-deoxycholate) supplemented with a complete protease inhibitor cocktail (Roche, Germany) and $1 \mathrm{mM}$ phenylmethylsulfonyl fluoride (PMSF).
Protein concentrations were measured by using a BCA protein assay. Protein extracts were separated in 12-15\% SDS-polyacrylamide (SDS-PAGE) gels, and then transferred onto nitrocellulose membranes (Advantec MFS Inc., Japan) using electroblotting. The membranes were blocked for $1 \mathrm{~h}$ in a PBST

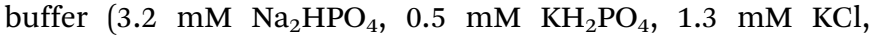
$135 \mathrm{mM} \mathrm{NaCl}, 0.05 \%$ Tween 20 , pH 7.4) containing 5\% nonfat milk. Following incubation with primary antibodies (antip53, anti-CC9, anti-CC7 abs were used to evaluate apoptosis, for DNA Damage; anti-gamma-H2A.X) and secondary antibodies, the blots were developed on X-ray films (Fuji, Japan) and signals were detected using a home-made chemiluminescence detection reagent (70 mM Tris HCL pH: 7.8; $225 \mu \mathrm{M}$ Coumaric acid, $1.25 \mathrm{mM}$ luminol, $0.011 \%$ hydrogen peroxide and $\mathrm{dH}_{2} \mathrm{O}$ up to $10 \mathrm{~mL}$ ).

\subsection{Cellular uptake and intracellular localization studies}

HeLa cells were incubated with free Dox and Dox-loaded SPION-NIPAM02 for 2.5, 5, 10 and 20 hours at 25, 37 and $42{ }^{\circ} \mathrm{C}$. Then, the cells were fixed in $4 \%$ formaldehyde, washed with PBS and stained with DAPI. Imaging was performed using an Olympus Xcellence RT microscope with phase contrast, DAPI and Cy3 filters. Internalization of nanoparticles was monitored with non-fixed live cells using an Olympus IX81 inverted microscope equipped with a $37{ }^{\circ} \mathrm{C}$ heating plate and a $5 \% \quad \mathrm{CO}_{2}$ chamber. The cells were treated with SPIONPNIPAM02-Dox and imaged at $10 \mathrm{~min}$ intervals for $20 \mathrm{~h}$ under a $10 \times$ objective. $645 \mathrm{~nm}$ per pixel resolution images were analyzed using ImageJ software (supporting video, ESI $\dagger$ ).

For endocytic internalization and endosomal escape tests, Dox-loaded SPION-PNIPAM (01 and 02) nanoparticles were applied onto the HeLa cells that were grown on cover-slides and that were previously transfected with a fluorescent Rab5 (marker of early endosomes) or Rab9 (marker of late endosomes) construct. The cells were fixed in 4\% PFA and the cover slides were mounted using 50\% glycerol in PBS. Intracellular localizations were analyzed using a confocal laser microscopy system (Carl-Zeiss LSM 710, Germany) using $488 \mathrm{~nm}$ (Dox) and $405 \mathrm{~nm}$ (Rab proteins) excitation wavelengths.

\subsection{Characterization}

FT-IR spectra of all materials were recorded on a Nicolet IS10 ATR-IR spectrophotometer from Thermo Scientific Inc. with $2 \mathrm{~cm}^{-1}$ resolution. Absorbance and transmittance were measured with a UV3600 Shimadzu UV-VIS-NIR spectrophotometer. Photoluminescence was measured by a Horiba Jobin-Yvon Fluoromax-3 spectrofluorometer.

TGA Q500 (TA Instruments) was used to determine the organic content of the nanoparticles. A constant ramping temperature program $\left(10{ }^{\circ} \mathrm{C} \min ^{-1}\right.$ up to $\left.600{ }^{\circ} \mathrm{C}\right)$ was used in the experiments under nitrogen flow. The hydrodynamic size of the particles and the zeta potential were determined by a Zetasizer Nano Series ZS at different temperatures with $173^{\circ}$ backscattered angle. The average crystal size, size distribution and morphology of the PNIPAM-coated superparamagnetic 
iron oxide nanoparticles were investigated by transmission electron microscopy (TEM).

The saturation magnetization of dried samples, packed in suitable capsule containers, was determined using a superconducting quantum interference device magnetometer (Cryogenic Limited PPMS system) in the applied field range of -1 to $1 \mathrm{~T}$, at $298 \mathrm{~K}$ at Middle East Technical University. The Fe content of samples was determined by ICP. For this purpose $200 \mu \mathrm{L}$ of stock solution was digested with $200 \mu \mathrm{L}$ concentrated nitric acid $\left(\mathrm{HNO}_{3}\right)$ and $200 \mu \mathrm{L}$ concentrated sulfuric acid $\left(\mathrm{H}_{2} \mathrm{SO}_{4}\right)$. Then the sample digest was diluted with distilled water, fortified with internal standards, and analyzed using inductively coupled plasma mass spectrometry (ICP-MS) and inductively coupled plasma optical emission spectrometry (ICP-OES) depending on the iron being monitored.

The molecular weights of the polymers grown from the SPION surface were measured by gel permeation chromatography (GPC) (Agilent 1100) equipped with a refractive index detector. A Polymer Labs PL Aquagel-OH Mixed $8 \mu \mathrm{m}$ column was used. The samples were prepared at $2.0 \mathrm{mg} \mathrm{mL}{ }^{-1}$ concentration and $50 \mu \mathrm{L}$ injection volumes were used. The SPION-PNIPAM particles were treated with concentrated $\mathrm{HCl}(37 \%)$ overnight and the polymer was extracted with chloroform. The polymer solutions were filtered through $0.20 \mu \mathrm{m}$-pore-size filters before injection. $\mathrm{pH} 7$ buffer containing $0.02 \mathrm{wt} \% \mathrm{NaN}_{3}$ at a flow rate of $1.0 \mathrm{~mL} \mathrm{~min}^{-1}$ at $25{ }^{\circ} \mathrm{C}$ was used for elution. Molecular weights are reported according to the calibration curve created with poly(acrylic acid)-sodium salt standards (Polymers Labs) with narrow polydispersity and molecular weights in the range of $1.25 \times 10^{3}$ and $1.10 \times 10^{6} \mathrm{Da}$.

For the relaxivity measurements, $1.5 \mathrm{~mL}$ of nanoparticles at seven different concentrations $(0.05-1 \mathrm{mM}$ based on Fe concentration) was prepared in doubly distilled water in glass vials $(10 \mathrm{~mm}$ diameter, $20 \mathrm{~mm}$ height). These vials were then placed in a 3T MRI scanner (Siemens Magnetom Trio, $f_{0}=123.24 \mathrm{MHz}$ ) and were imaged at room temperature, using a 32-channel head coil. The $T_{1}$ relaxation times were measured via an inversion recovery turbo spin echo sequence with $\mathrm{TR}=2000 \mathrm{~ms}$ repetition time and $\mathrm{TE}=$ $12 \mathrm{~ms}$ echo time. Ten different inversion times were utilized: $\mathrm{TI}=[24,100,200,400,600,800,1000,1250,1500,1900] \mathrm{ms}$. The $T_{2}$ relaxation times were measured using a single-echo spin echo sequence with $\mathrm{TR}=3000 \mathrm{~ms}$. Thirteen different echo times were

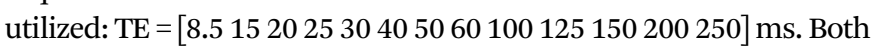
the $T_{1}$ and $T_{2}$ measurement sequences had a $256 \times 256$ acquisition matrix over $15 \times 15 \mathrm{~cm}^{2}$ FOV, and $4 \mathrm{~mm}$ slice thickness.

The MRI images were then analyzed in MATLAB (Mathworks, Natick, MA) using an in-house script. A circular region of interest (ROI) was chosen manually over each vial, and the pixel intensities as a function of TI were fitted to the following $T_{1}$ relaxation curve via Levenberg-Marquardt nonlinear fit:

$$
S=S_{0}\left[1-2 \mathrm{e}^{-\frac{\mathrm{TI}}{T_{1}}}+\mathrm{e}^{-\frac{\mathrm{TR}}{T_{1}}}\right]
$$

Similarly for $T_{2}$-weighted images, the pixel intensities as a function of TE were fitted to the following $T_{2}$ relaxation curve:

$$
S=S_{0} \mathrm{e}^{-\frac{\mathrm{TE}}{T_{2}}}
$$

Finally, the $T_{1}$ and $T_{2}$ relaxation times as a function of concentration, $C$, were fitted to the following linear curves to determine $r_{1}$, the longitudinal relaxivity, and $r_{2}$ the transverse relaxivity values:

$$
\frac{1}{T_{x}}=\frac{1}{T_{(x, 0)}}+r_{x} \cdot C
$$

In this equation, $x$ is either 1 or 2.

\section{Results and discussion}

\subsection{Immobilization of ATRP initiator on SPIONs and surface- initiated polymerization of PNIPAM}

In surface-initiated polymerization reactions covalent attachment of the initiator to the particle surface is crucial to sustain stability and prevent aggregation of the inorganic core as a result of initiator desorption. Since we aim to have small-sized SPIONPNIPAM nanoparticles, an ATRP initiator was covalently attached to the pre-made SPION surface. Silanes are known to bind SPION surfaces via sol-gel chemistry forming $\mathrm{Fe}-\mathrm{O}-\mathrm{Si}$ bonds. Hence, an ATRP initiator (BPTMS) with a trimethoxysilane group was synthesized from APTMS and $\alpha$-bromoisobutyryl bromide in a simple amidation reaction. As shown in Scheme 1, SPION-PNIPAM nanoparticles were prepared in three steps: (1) synthesis of fatty acid-coated SPIONs, (2) immobilization of an ATRP initiator onto the SPIONs, and (3) polymerization of PNIPAM from the SPION surface. Initially, lauric acid-coated SPIONs were prepared from iron salts under basic conditions in water, then BPTMS was used to exchange LA from the surface of the SPIONs and bound to the surface under basic conditions favoring silane hydrolysis (Scheme 1). This is more advantageous over attaching an initiator on the bare iron oxide surface to reduce core aggregation. Then, surface-initiated ATRP of NIPAM was carried out in a mixed solvent system from the initiator-modified SPION surface using $\mathrm{Me}_{6}$ TREN (ligand) and $\mathrm{CuCl}$ (catalyst). Although polymerization of acrylamides by ATRP in organic media is not facile, we have had considerable success growing PNIPAM chains from the SPION surface in water-organic mixed solvent systems since water accelerates the reaction. Two different reaction conditions were used in order to grow different lengths of PNIPAM from the surface. PNIPAM01 was synthesized in a water/DMF/THF mixed solvent system at $30{ }^{\circ} \mathrm{C}$ and PNIPAM02 was prepared in a water/DMF/EtAc mixture at $70{ }^{\circ} \mathrm{C}$ (Table 1$)$.

\subsection{Characterization of the nanoparticles}

FT-IR analysis confirms successful exchange of LA and functionalization of the SPIONs with BPTMS (Fig. 1a). The spectrum of the BPTMS-SPIONs shows the specific $\mathrm{N}-\mathrm{H}$ stretching (3350 $\left.\mathrm{cm}^{-1}\right), \mathrm{C}=\mathrm{O}$ stretching $\left(1630 \mathrm{~cm}^{-1}\right), \mathrm{N}-\mathrm{H}$ bending $1540 \mathrm{~cm}^{-1}$, Si-O stretching $\left(1110 \mathrm{~cm}^{-1}\right)$ and $\mathrm{C}-\mathrm{Br}\left(622 \mathrm{~cm}^{-1}\right)$ bands along with the disappearance of major $\mathrm{C}=\mathrm{O}$ stretching at $1519 \mathrm{~cm}^{-1}$. The broad absorption band at $3300 \mathrm{~cm}^{-1}$ in the spectrum of SPION-PNIPAM is due to the overlap of $-\mathrm{NH}$ and $\mathrm{CH}_{2}$ stretching vibrations which is attributable to successful polymerization of NIPAM from the SPION surface along with intense amide $\mathrm{N}-\mathrm{H}$ peaks at $3169 \mathrm{~cm}^{-1}$ and $1506 \mathrm{~cm}^{-1}$. 

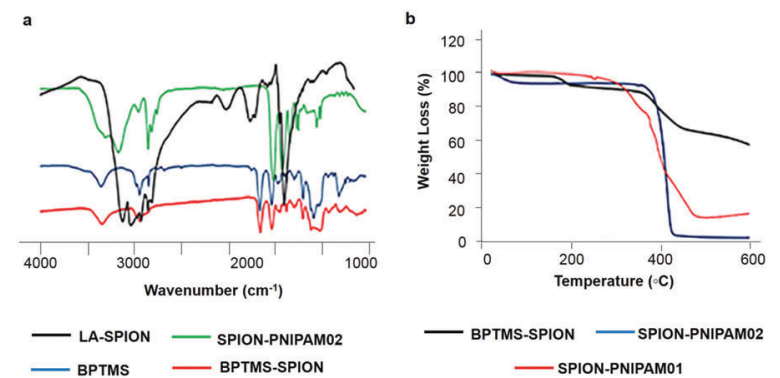

- BPTMS BPTMS-SPION

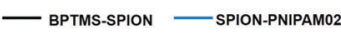

Fig. 1 (a) FT-IR spectra of LA-coated SPIONs (black), BPTMS (blue), BPTMS functionalized SPIONs (red) and SPION-PNIPAM (green). (b) Thermogravimetric analysis of the ATRP initiator functionalized nanoparticles (BPTMS-SPIONs) and PNIPAM modified SPIONs (SPIONPNIPAM01 and 02).

The amount of the initiator bound on the SPION surface and the amount of the polymer grown from the surface were calculated from the weight loss determined by thermogravimetric analysis (TGA) (Fig. 1b). The initiator content was determined as $34 \mathrm{wt} \%$. The dramatic weight loss of the SPION-PNIPAM samples at $370-435{ }^{\circ} \mathrm{C}$ originates from the degradation of the polymer coating. Hence, the organic content of SPION-PNIPAM01 and SPION-PNIPAM02 was determined as 85 and $91 \mathrm{wt} \%$, respectively. The higher organic content of SPION-PNIPAM02 indicates the formation of higher molecular weight PNIPAM in the second preparation. The GPC analysis of the cleaved PNIPAM01 has 20.4 kDa Mn with 1.54 PDI. Yet, we could not measure the molecular weight of PNIPAM02 by GPC.

The crystal size of the iron oxide core was determined as $7.2 \pm 2.7 \mathrm{~nm}$ from the TEM (Fig. S1, ESI $\dagger$ ). The hydrodynamic size of the SPION-PNIPAMs and its temperature dependency were determined with DLS (Fig. 2a-d). The average hydrodynamic size of SPION-PNIPAM01 at $25{ }^{\circ} \mathrm{C}$ was $57 \mathrm{~nm}$ and that of SPION-PNIPAM02 was $8.55 \mathrm{~nm}$ (Fig. 2a and c). At this temperature, PNIPAM chains were well hydrated and provided a steric stabilization that prevented dramatic aggregation. The smaller average hydrodynamic size measured for PNIPAM02 may be due to more successful steric stabilization achieved by the longer polymer chains which reduced aggregation dramatically. The hydrodynamic size of SPION-PNIPAM01 was increased at $30{ }^{\circ} \mathrm{C}$, signaling the aggregation induced by increasing hydrophobicity as the temperature gets closer to the LCST of PNIPAM. Increasing the temperature to $35{ }^{\circ} \mathrm{C}$ leads to decrease in hydrodynamic size due to the loss of hydration and collapse of polymer chains on the crystal surface. Above the LCST at $40{ }^{\circ} \mathrm{C}$, the polymer chains become relatively hydrophobic, and polymer-polymer interaction becomes dominant which causes aggregation of particles (about $150 \mathrm{~nm}$ ). Yet, the change in the hydrodynamic diameter is reversible, which can be exploited as an on-off mechanism. Fig. 2b shows the temperature-dependent transmittance of SPION-PNIPAM01 at $500 \mathrm{~nm}$. Above $30{ }^{\circ} \mathrm{C}$, transmittance started to decrease dramatically as particles started to aggregate upon dehydration and increasing hydrophobic interactions. LCST of SPIONPNIPAM01 was determined as $38{ }^{\circ} \mathrm{C}$ from this plot. As the

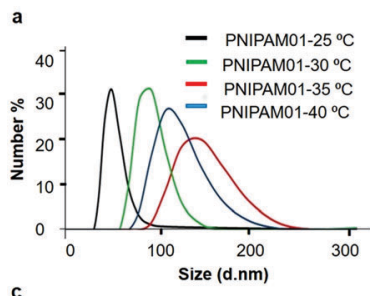

b
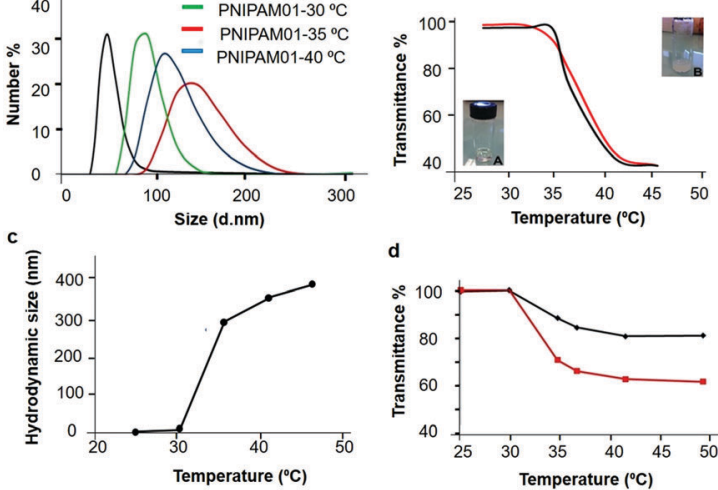

d

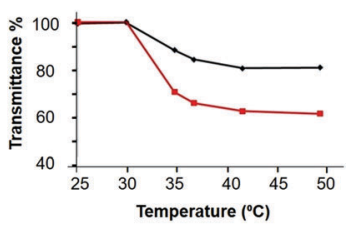

Fig. 2 (a) Hydrodynamic size of aqueous SPION-PNIPAM01 measured by DLS as a function of temperature. (b) Turbidity measurements of SPION-PNIPAM01 (0.4 $\mathrm{mg} \mathrm{mL}^{-1}$ aqueous solution) as a function of temperature. Red line represents heating cycle and black line represents cooling cycle. Inset: Photographs of the samples (A) at room temperature $\left(25^{\circ} \mathrm{C}\right.$ ) and (B) at $40{ }^{\circ} \mathrm{C}$. (c) Hydrodynamic size of aqueous SPIONPNIPAM02 as a function of temperature. (d) Temperature-dependent turbidity measurements of SPION-PNIPAM01 (black line) and SPIONPNIPAM02 (red line) in PBS solution.

temperature was reduced back to room temperature, a clear solution with regained transmittance was obtained (Fig. 2b).

SPION-PNIPAM02 had similar behavior with increasing hydrodynamic size above $30{ }^{\circ} \mathrm{C}$, and much larger aggregates (about $350 \mathrm{~nm}$ ) above the LCST. Comparison of the aggregate size obtained from the two particles above the LCST indicates that with increasing molecular weight of the PNIPAM coating, a larger aggregate was obtained. Besides there was no significant size increase between $25{ }^{\circ} \mathrm{C}$ and $30{ }^{\circ} \mathrm{C}$, unlike SPION-PNIPAM01 (Fig. 2c). This is possibly due to the longer polymeric chains of PNIPAM in SPION-PNIPAM02. The length of the coating molecules directed outward from the surface is critical for steric stabilization and hydrophobic interactions. Increasing chain length does provide better interaction between the particles during dehydration, which actually causes less interaction in the hydrated state.

The thermo-sensitivity of the surface-grafted PNIPAMs was also investigated in a simulated physiological solution, PBS, at $0.023 \mathrm{mg} \mathrm{mL} \mathrm{mL}^{-1}$ concentration. The dramatic decrease in the transmittance at $35{ }^{\circ} \mathrm{C}$ confirms that thermo-responsive behavior was maintained in physiological solutions (Fig. 2d).

\subsection{Magnetization and potential as MRI contrast agent}

The magnetic properties of the as-synthesized SPION-PNIPAM01 and 02 nanoparticles were studied with VSM. The variation of magnetization $(M)$ versus the applied magnetic field $(H)$ measured at $298 \mathrm{~K}$ is shown in Fig. S2 (ESI $\dagger$ ). The magnetization increases with increasing magnetic field and saturates at higher magnetic fields (above 0.5 T). The coercive field and remanence magnetization is very small for both nanoparticles. These are characteristics of superparamagnetic nanoparticles. ${ }^{37}$ Saturation magnetizations $\left(M_{\mathrm{S}}\right)$ were calculated as 0.89 and $0.15 \mathrm{emu}^{-1}$ for the SPION-PNIPAM01 and SPION-PNIPAM02 nanoparticles, 

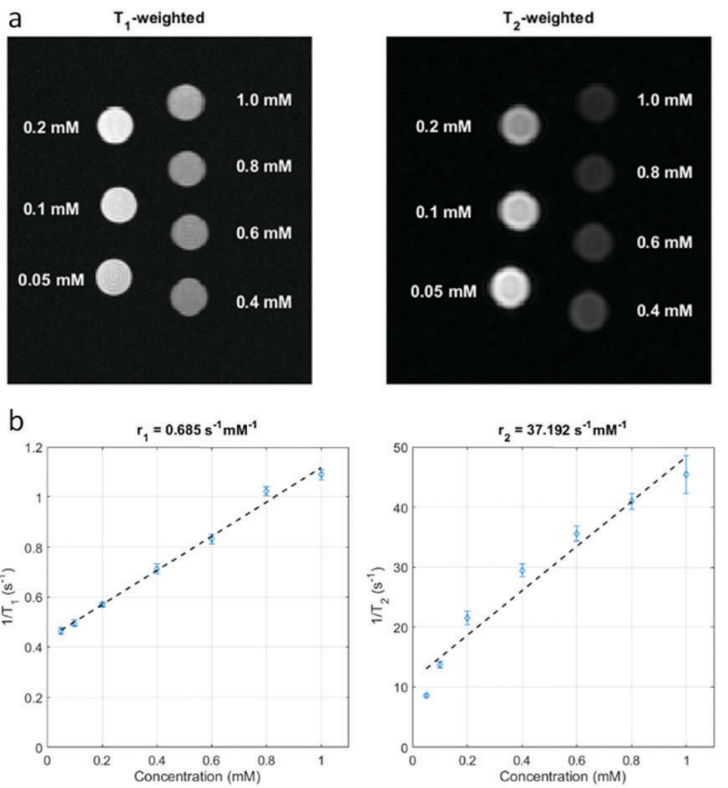

Fig. 3 (a) Example $T_{1}$-weighted and $T_{2}$-weighted $M R I$ images at $3 T$. The $T_{1}$-weighted image was acquired with $\mathrm{TI}=24 \mathrm{~ms}$, TR/TE $=2000 / 12 \mathrm{~ms}$, and the $T_{2}$-weighted image was acquired at TR/TE $=3000 / 60 \mathrm{~ms}$. The iron concentration of each vial is indicated inside the images. (b) Measured relaxivities, $r_{1}$ and $r_{2}$, for the nanoparticles at 3T. Graphics display the change in the inverse of relaxation times (i.e., relaxation rates) as a function of iron concentration $(0.05,0.1,0.2,0.4,0.6,0.8,1 \mathrm{mM})$. The error bars denote the mean and the standard deviation of the relaxation rates from all the pixels on the selected ROls for each vial. The dashed lines show the linear fit to all data points.

respectively (Fig. 3a). Considering the high organic content of these particles such values are reasonable and in agreement with the literature. ${ }^{38}$

This superparamagnetic property can be exploited for contrast generation in MRI. Seven dilutions of SPION-PNIPAM01 $(0.05,0.1,0.2,0.4,0.6,0.8,1 \mathrm{mM}$ Fe concentration) were placed in a $3 \mathrm{~T}$ MRI and the $T_{1}$ and $T_{2}$-weighted phantom images were recorded. The example $T_{1}$-weighted and $T_{2}$-weighted images are shown in Fig. $3 \mathrm{a}$ for $\mathrm{TI}=24 \mathrm{~ms}$ and $\mathrm{TE}=60 \mathrm{~ms}$, respectively. Fig. $3 \mathrm{~b}$ shows the measured relaxivities $r_{1}$ and $r_{2}$ for the nanoparticles at 3T. The relaxivity values of $r_{1}=0.685 \mathrm{mM}^{-1} \mathrm{~s}^{-1}$ and $r_{2}=37.2 \mathrm{mM}^{-1} \mathrm{~s}^{-1}$ were obtained from the slopes of these plots.

Overall, SPION-PNIPAM generates a significant contrast in the $\mathrm{T} 2$ mode and hence, holds potential as a diagnostic probe as expected. ${ }^{38,39}$

\subsection{Dox encapsulation and release}

Dox was loaded into thermo-responsive SPION-PNIPAM in both DIW and PBS buffer (pH: 7.4) at the NP/Dox (w/w) ratio of $10: 1$.

In our case, the Dox-loading efficiency was $12 \%$ and $30 \%$ in DIW but dramatically increased to $68 \%$ and $96 \%$ for SPIONPNIPAM01 and SPION-PNIPAM02, respectively, in PBS (Fig. 4a). This means 6.8 and $9.6 \mathrm{wt} \%$ of the nanoparticles are active drugs which is quite high compared to similar systems reported in the literature. The lower solubility of Dox in PBS provided
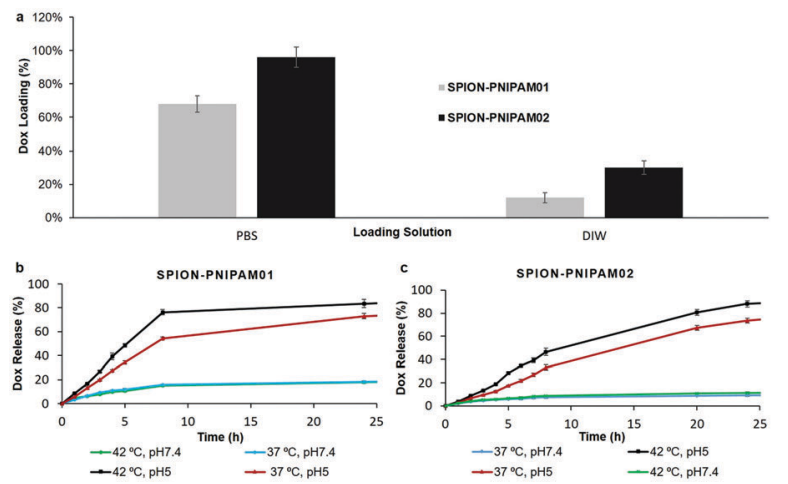

Fig. 4 (a) Dox-loading efficiency on SPION-PNIPAM01 and SPIONPNIPAM02 nanoparticles in PBS buffer and DIW. (b) Release of Dox from SPION-PNIPAMO1 and (c) SPION-PNIPAMO2 at pH 5 and pH 7.4 at $37^{\circ} \mathrm{C}$ and $42{ }^{\circ} \mathrm{C}$.

better drug loading. At room temperature where the PNIPAM corona is hydrated and permeable, Dox is loaded into PNIPAM via electrostatic interactions. These results also confirm that by increasing the PNIPAM molecular weight, higher doses of Dox can be encapsulated in the organic corona of the nanoparticles. Previously, Purushotham et al. studied Dox release under hyperthermia with $2.5 \mathrm{wt} \%$ Dox-loaded PNIPAM $/ \gamma-\mathrm{Fe}_{2} \mathrm{O}_{3}$ produced by dispersion polymerization. ${ }^{40}$ Habibi et al. reported $4.5 \mathrm{wt} \%$ Dox loading to SPION/P(NIPAM-co-NVP) and about $80 \%$ release in 100 hours at $\mathrm{pH} 5.8 .^{26}$ Similarly, Wu et al. achieved $10 \mathrm{wt} \%$ Dox loading into SPION-P(NIPAM-co-AA) nanospheres. However, the sizes of their particles were 236$387 \mathrm{~nm}$ which is large for drug delivery applications and they observed about $50 \%$ drug release in 500 min under acidic $\mathrm{pH}$ and $37{ }^{\circ} \mathrm{C}^{27}$ Magnetite nanoclusters with crosslinked PNIPAM loaded with Dox were also reported to have quite large hydrodynamic size $(350 \mathrm{~nm})$ with aggregated magnetic cores $(100 \mathrm{~nm})$ and poor stability along with only 50\% drug release in $24 \mathrm{~h}$ (acidic $\mathrm{pH}$ and $37{ }^{\circ} \mathrm{C}$ ). ${ }^{4}$ Eyiler et al. grew poly(itaconic acid-co-NIPA) from the SPION surface via surface-initiated ATRP but got a bimodal particle size distribution around $100 \mathrm{~nm}$ and $250 \mathrm{~nm}$ due to the aggregated structure of the initiator-bound SPIONs. ${ }^{34}$ Compared to these previous reports, stable and small SPION-PNIPAM nanoparticles produced via the grafting from technique here are better alternatives, especially when such particle properties are coupled with high DOX-loading capacity.

Dox release from the SPION-PNIPAM02 nanoparticles was studied up to 48 hours under six different conditions: namely, in phosphate (pH 5) and PBS buffers (pH 7.4) at $22{ }^{\circ} \mathrm{C}, 37{ }^{\circ} \mathrm{C}$ and $42{ }^{\circ} \mathrm{C}$ (Fig. S3 ESI, $\dagger$ and Fig. 4c). At low temperature $\left(22^{\circ} \mathrm{C}\right)$, Dox release was $10.7 \%$ and independent of the $\mathrm{pH}$ in $48 \mathrm{~h}$ (Fig. S3, ESI $\dagger$ ). This indicates the stability of the complex at lower temperatures. Recently, Wu et al. reported the synthesis of a poly(2-dimethylaminoethyl methacrylate)- $b$-PNIPAM shell on SPIONs by ATRP for thermo-responsive release of Dox. ${ }^{33}$ However, the Dox-loaded particles have shown higher drug release profile at $25{ }^{\circ} \mathrm{C}$ than at $37{ }^{\circ} \mathrm{C}$ which is opposite to the desired behavior. In our study, at neutral $\mathrm{pH}$, the impact of 
temperature on the release of Dox is minimal, reaching $18 \%$ at $42{ }^{\circ} \mathrm{C}$ in $48 \mathrm{~h}$. This is very important to protect the drug from early release in the blood stream or in normal tissue under physiological conditions (Fig. 4c and Fig. S3, ESI $\dagger$ ). However, a dramatic temperature-dependent difference was observed at pH 5 indicating that both temperature and acidic $\mathrm{pH}$ regulate the release of Dox from these nanoparticles, due to the LCST of the polymer and the electrostatic binding of the drug to the polymer. Major Dox release was observed within $24 \mathrm{~h}$ reaching a 6.8 and 8 -fold increase at $37{ }^{\circ} \mathrm{C}$ and $42{ }^{\circ} \mathrm{C}$ compared to the release at $22{ }^{\circ} \mathrm{C}$ at pH 5 (Scheme 2 and Fig. 4c). This means about $11 \%, 73 \%$ and $88 \%$ Dox are released at $22{ }^{\circ} \mathrm{C}, 37{ }^{\circ} \mathrm{C}$ and $42{ }^{\circ} \mathrm{C}$ in $24 \mathrm{~h}$. Overall, at the end of $48 \mathrm{~h}$ the total release reached $95 \%$ at 37 and $42{ }^{\circ} \mathrm{C}$ but stayed below $20 \%$ at $22{ }^{\circ} \mathrm{C}$. In the case of SPION-PNIPAM01, where there is less polymeric content, a faster drug release was observed. The major Dox release was observed in the first $8 \mathrm{~h}$ in acidic $\mathrm{pH}$ : about 54 and $76 \%$ at 37 and $42{ }^{\circ} \mathrm{C}$. At the end of $24 \mathrm{~h}$ the total release reached $73-83 \%$ at 37 and $42{ }^{\circ} \mathrm{C}$ (Fig. $4 \mathrm{~b}$ ). The temperature-independent Dox release at pH 7.4 was below $20 \%$ in $24 \mathrm{~h}$. Under the most favorable Dox release conditions (pH 5 and $42{ }^{\circ} \mathrm{C}$ ) about $80 \%$ Dox was released from SPION-PNIPAM01-Dox in $8 \mathrm{~h}$, while the same release was achieved in $20 \mathrm{~h}$ with SPION-PNIPAM02-Dox. Overall, Dox release from SPION-PNIPAM02-Dox is slower although it reaches similar release amounts in $24 \mathrm{~h}$. This may be due to longer polymer chains and higher polymer content which affect the response time and drug-polymer interaction.

There are two very critical features here: $\mathrm{pH}$-independent low release of Dox at physiological $\mathrm{pH}$ and high drug release in endosomal $\mathrm{pH}$ which increased significantly above the LCST of the polymer which potentially can be achieved via hyperthermia. Significant Dox release under physiological conditions has been reported before by Rahimi et al. ${ }^{41}$ About 18-28-60\% Dox was released from SPIONs coated with a PNIPAM copolymer at 4-37-41 ${ }^{\circ} \mathrm{C}$, respectively, at neutral pH. Similarly, PNIPAM copolymer-coated magnetic nanoparticles with $0.35 \mathrm{~g}$ Dox per g NP were reported but with 30 and $70 \%$ release in PBS at 37 and $42{ }^{\circ} \mathrm{C}$, in $48 \mathrm{~h}$, which means almost twice as much drug

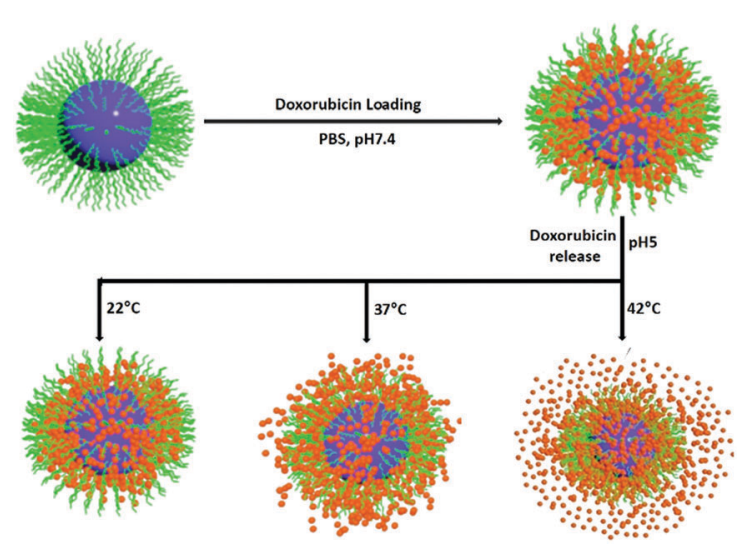

Scheme 2 Scheme representation of Dox loading on SPION-PNIPAM in PBS and dual responsive release in acidic buffer $(\mathrm{pH} 5)$ at three different temperatures $\left(37^{\circ} \mathrm{C}, 22^{\circ} \mathrm{C}\right.$, and $\left.42^{\circ} \mathrm{C}\right)$. release under physiological conditions compared to our SPIONPNIPA-Dox. ${ }^{41}$ However, the Dox release rate in our study is temperature dependent only at acidic $\mathrm{pH}(\mathrm{pH} 5)$ and Dox is mostly maintained within the nanoparticles at neutral $\mathrm{pH}$ and body temperature, which is very crucial for biomedical applications, meaning that Dox will be protected in the blood stream and not get distributed systemically. This can reduce the side effects of Dox dramatically, especially if targeting to the tumor is also achieved. The slightly higher acidity of the tumor microenvironment would be beneficial for the study as well. Overall, when high Dox-loading content (6.8-9.6 wt\%) combined with dually responsive high release rate (about $80 \%$ on average in $24 \mathrm{~h}$ ) and stability under physiological conditions are considered, the SPION-PNIPAM particles are very promising theranostic particles.

\subsection{Determination of toxicity}

Biocompatibility of the carrier itself is crucial in the development of safe drug delivery systems. We performed both an MTT assay which is based on the metabolic activity and a trypan blue dye exclusion assay which is based on the integrity of the cellular membrane. MTT indicates around 90\% viable cells in $72 \mathrm{~h}$ for both SPION-NIPAM nanoparticles (Fig. 5a and b) even at $1000 \mu \mathrm{g} \mathrm{mL}{ }^{-1}$ dose which is 8 times higher than the dose that was applied with Dox. In agreement with this, less than $15 \%$ dead cells were determined for either particle (Fig. $5 \mathrm{c}$ and d). On the other hand, both the SPION-PNIPAM-Dox formulations significantly decreased the cell viability in a dose and timedependent manner. Since at this concentration (1 mg) nanoparticles had no significant toxicity, the observed effect is mainly due to delivered and released Dox. Both the assays indicate that SPION-PNIPAM01-Dox has higher cytotoxicity than SPION-PNIPAM02-Dox at the same concentrations of Dox $\left(0.3\right.$ and $\left.1.3 \mu \mathrm{g} \mathrm{mL}{ }^{-1}\right)$. This is expected due to the faster Dox release seen with the first nanoparticles. In the meantime, the application of $1.3 \mu \mathrm{g} \mathrm{mL} \mathrm{m}^{-1}$ concentration of free Dox to HeLa cells resulted in about $90 \%$ cell death and only about $15-20 \%$ viability in $48-72 \mathrm{~h}$. Since free Dox rapidly passes through the cytoplasm membrane and diffuses into the nuclei, it shows a cytotoxic effect very rapidly. When the same amount
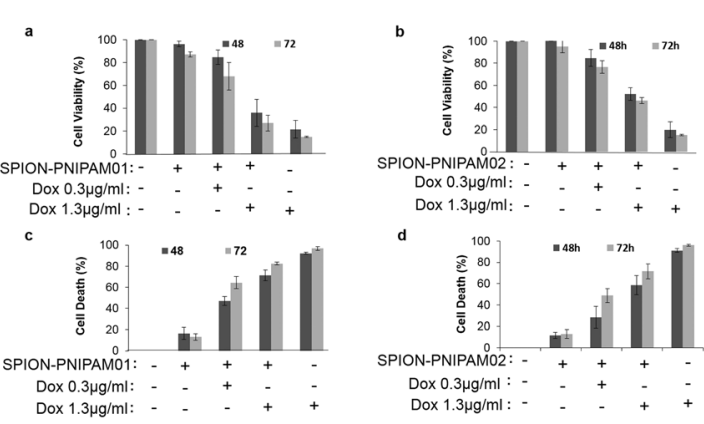

Fig. 5 Toxicity of SPION-PNIPAM (01 and 02), SPION-PNIPAM (01 and 02)-Dox and free Dox on HeLa cells assessed by ( $a$ and b) MTT and (c and d) Trypan blue dye exclusion assays after 48 and $72 \mathrm{~h}$ incubation. Data are shown as the mean \pm SD $(n=3)$. 
$c$

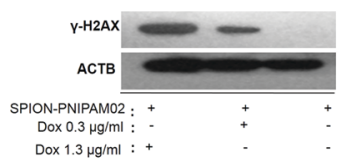

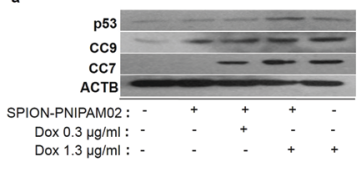

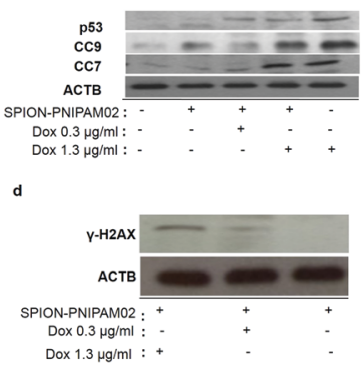

Fig. 6 (a and b) Apoptosis and (c) and (d) DNA damage markers analyzed in cellular extracts of nanoparticle-treated HeLa cells. Free Dox at $1.3 \mu \mathrm{g} \mathrm{mL}^{-1}$ and SPION-PNIPAM-Dox nanoparticles at a dose equivalent to 0.3 and $1.3 \mu \mathrm{g}$ Dox per $\mathrm{mL}$ was used. Non-treated cells were used as a control.

of Dox is delivered with the nanoparticles, the toxicity was close to the toxicity of free Dox with SPION-NIPAM-01. About 70-80\% cell death with $25-35 \%$ viability was determined with SPIONPNIPAM01-Dox at 48 and $72 \mathrm{~h}$, respectively. In the case of SPION-PNIPAM02-Dox, the cell death was $68-70 \%$ and the viability was $45-50 \%$ in again 42 and $72 \mathrm{~h}$, respectively.

Apoptosis is a classical type of cell death mechanism that is characterized by the activation of initiator (e.g. caspase 9) and effector (e.g. caspase 7) caspase enzymes. The contribution of apoptosis to the toxicity of particles was confirmed by the presence of cleaved caspase 9 (cc9) and cleaved caspase 7 (cc7) in the cellular extracts of the SPION-PNIPAM (01 and 02)-Dox nanoparticles. Also, expression/stabilization of p53, a known tumor suppressor protein and one of the main upstream factors in apoptosis, was checked. The results indicate the SPION-PNIPAM nanoparticles alone did not induce apoptosis, but similar to free Dox, Dox-loaded nanoparticles killed the cells by apoptosis. The levels of cc9, cc7, and p53 were all augmented parallel to increasing Dox content of the nanoparticles. In general, Dox-loaded SPION-PNIPAM01 induced more apoptosis than Dox-loaded SPION-PNIPAM02, and the results were comparable to the apoptotic effects of free Dox at $1.3 \mu \mathrm{g} \mathrm{mL} \mathrm{m}^{-1}$ Dox concentration (Fig. 6a and b). These results are in agreement with the toxicity results discussed above.

Fragmentation of DNA is another late event during the apoptosis type of cell death. Following the formation of DNA double-strand breaks, one of the histone variants, gamma $\mathrm{H} 2 \mathrm{AX}$, gets phosphorylated by a kinase, allowing the recruitment of the DNA repair machinery to the lesion. ${ }^{42}$ Therefore, in order to identify DNA damage, we checked phosphorylation of gamma$\mathrm{H} 2 \mathrm{AX}$ in our system and observed phospho gamma-H2AX accumulated after treatment with Dox-loaded nanoparticles. ${ }^{43-45}$ More importantly, Dox-loaded SPION-PNIPAM01 or SPION-PNIPAM02 particles were clearly more potent inducers of DNA damage compared to free Dox. These data are also in line with the toxicity and apoptosis tests that were shown above (Fig. 6c and d).

\subsection{Endocytic internalization of SPION-PNIPAM-Dox}

The time dependence of internalization, drug release and intracellular localization of SPION-PNIPAM02-Dox and free Dox in cells were studied. Different drug concentrations (equivalent of $0.3-10 \mu \mathrm{g} \mathrm{mL}^{-1}$ Dox) were tested in 2.5 to 20 hour incubations. The red fluorescent signal originated from the Dox, and the blue signal came from the nuclear dye, DAPI. Endosomal accumulation of Dox was evident even in $2.5 \mathrm{~h}$ (Fig. 7a) at high doses when delivered with the nanoparticles. As seen in Fig. S4 (ESI $\dagger$ ), free Dox rapidly passed through the cell membrane and entered into the cell nuclei even in $2.5 \mathrm{~h}$ and at low dose which increases dramatically with incubation time and dose. ${ }^{46,47}$ Owing to its hydrophobic anthracycline backbone and also very small size, Dox can pass through the cell and also nuclear a

$0.3 \mu \mathrm{g} / \mathrm{ml} \quad 0.6 \mu \mathrm{g} / \mathrm{ml} \quad 1.2 \mu \mathrm{g} / \mathrm{ml} \quad 2.5 \mu \mathrm{g} / \mathrm{ml} \quad 5 \mu \mathrm{g} / \mathrm{ml} \quad 10 \mu \mathrm{g} / \mathrm{ml}$

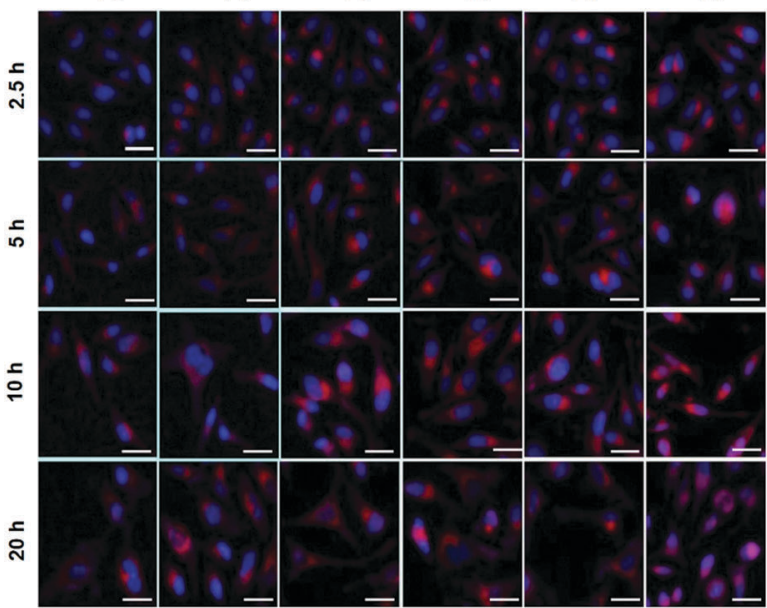

b

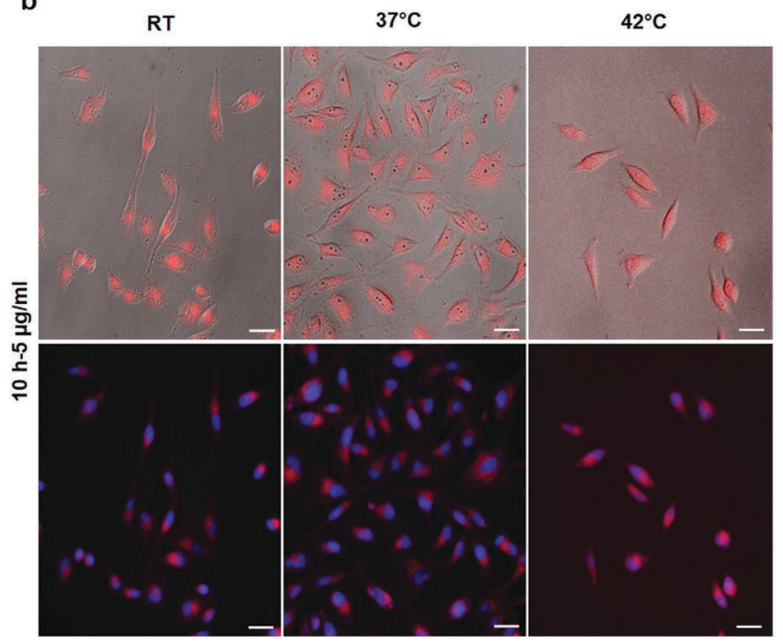

Fig. 7 (a) Xcellence RT life time microscopy images of HeLa cells treated with SPION-PNIPAM02-Dox at different concentrations (equivalent to 0.3, 0.6, $1.2,2.5,5$ and $10 \mu \mathrm{g} \mathrm{mL}^{-1}$ Dox) at $37{ }^{\circ} \mathrm{C}$. Images that were taken at different time points $(2.5,5,10$ and $20 \mathrm{~h})$ show the time and dose-dependent internalization of nanoparticles and diffusion of Dox to nuclei. (b) Fluorescence microscopy images of HeLa cells treated with SPION-PNIPAM02-Dox nanoparticles $10 \mathrm{~h}$ at $5 \mu \mathrm{g} \mathrm{mL}{ }^{-1}$ Dox concentration at room temperature, $37{ }^{\circ} \mathrm{C}$ and $42{ }^{\circ} \mathrm{C}$, separately, showing intracellular localization of Dox as a function of dose and incubation temperature. Blue: nuclear stain DAPI. Red: Dox. Scale bar $40 \mu \mathrm{m}$. 
membrane by diffusion which is driven by a concentration gradient across the membranes. ${ }^{48,49}$ SPION-PNIPAM-Dox nanoparticles, on the other hand, are very efficiently internalized by endocytosis but cannot enter the nucleus. Dox is slowly released from the nanoparticles in the endosomes and migrates to the nucleus, which makes nuclear localization slower than the free drug.

The influence of incubation temperature on the cell internalization, release and intracellular localization of the nanoparticles were studied, since Dox release is faster at and above the LCST of PNIPAM at acidic pH as described above. The intraluminal $\mathrm{pH}$ of endosomes decreases, as they mature from early endosomes to late endosomes and lysosomes. The $\mathrm{pH}$ of early endosomes is around 5.5 to 6.3 , whereas that of late endosomes is typically less than 5.5 . Lysosomes are the most acidic compartments in cells, with the internal $\mathrm{pH}$ being lower than 4.5. ${ }^{50,51}$ Confocal images of cells incubated with Doxloaded nanoparticles at different temperatures demonstrated that, at room temperature, most drug was entrapped inside endosomes even after 10 hours, whereas at $37^{\circ} \mathrm{C}$, Dox release was triggered and colocalization with nuclei increased reaching the highest concentrations in the nuclei at $42{ }^{\circ} \mathrm{C}$ (Fig. 7b). This is in agreement with the enhanced drug release observed only at pH 5 and temperature $37{ }^{\circ} \mathrm{C}$ with further release enhancement at $42{ }^{\circ} \mathrm{C}$ (Fig. 4c). The prominent difference between the drug release at 37 and $42{ }^{\circ} \mathrm{C}$ is a very valuable property for controlled release. It was achieved mainly due to the dual stimuli-sensitive nature of the SPION-PNIPAM nanoparticles, providing dramatic drug release above the LCST following internalization of the particles and in low $\mathrm{pH}$ cellular environments.

The internalization path and kinetics of the Dox-loaded SPION-PNIPAM nanoparticles in HeLa cells was further studied using compartment-specific markers. Rab5 is an early endosome marker and Rab9 is a late endosome-specific intracellular marker.

In time-dependent localization studies of nanoparticles, SPION-PNIPAM01-Dox showed a strong colocalization with Rab5
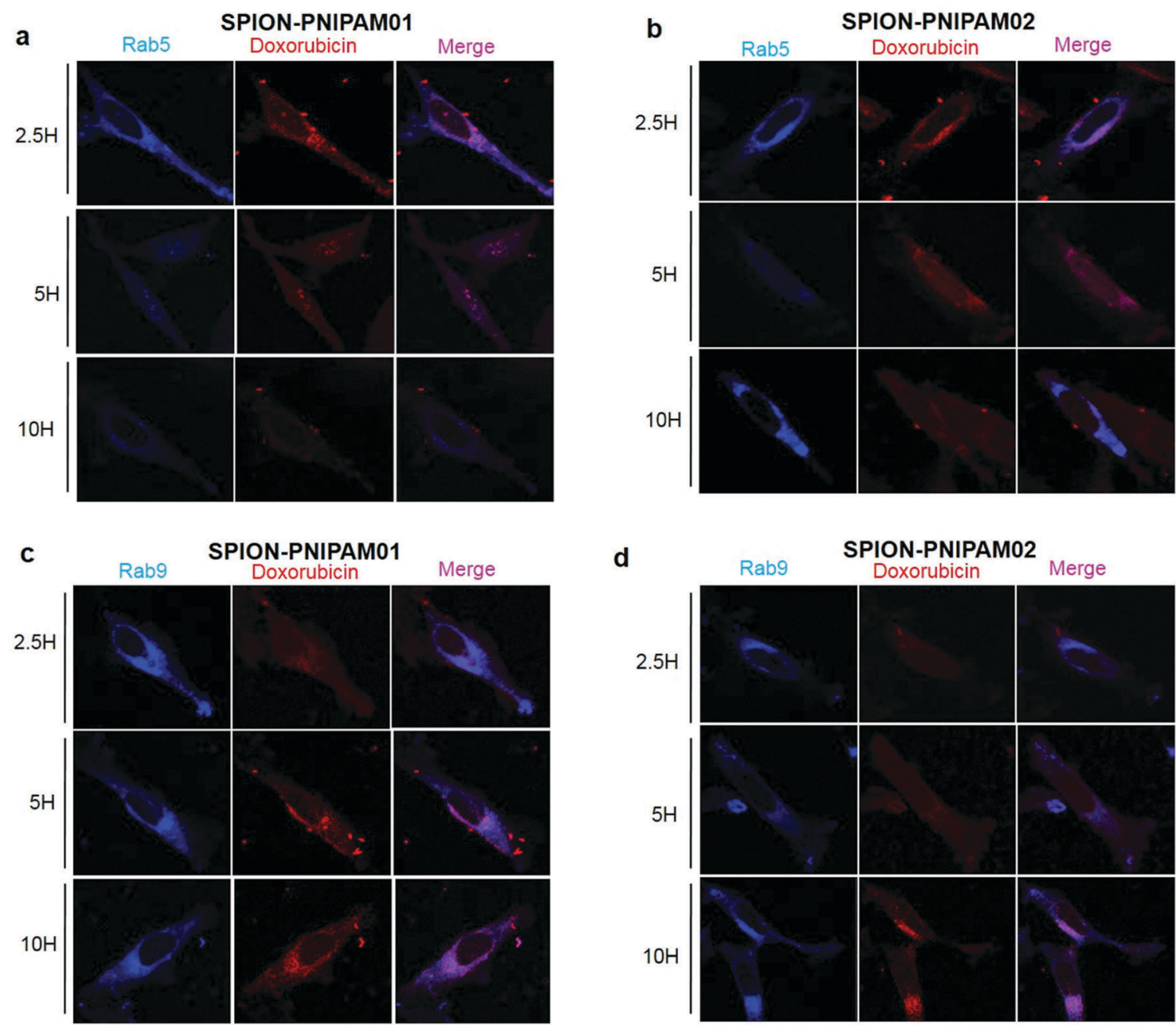

Fig. 8 Endocytic internalization of SPION-PNIPAM-Dox nanoparticles $\left(1.3 \mu \mathrm{g} \mathrm{mL}{ }^{-1}\right)$ by HeLa cells at $2.5 \mathrm{~h}, 5 \mathrm{~h}$ and $10 \mathrm{~h}$ incubation at $37{ }^{\circ} \mathrm{C}$. (a and b) Colocalization of the SPION-PNIPAM01-Dox and SPION-PNIPAM02-Dox nanoparticles in early endosomes. (c and d) Colocalization of the SPIONPNIPAM01-Dox and SPION-PNIPAM02-Dox nanoparticles in late endosomes. (Rab5; blue), (Rab9; blue), (Dox; red). 
and moderate colocalization with Rab9 at 2.5-5 h time points, but the colocalization signal then faded at $10 \mathrm{~h}$ in early endosomes (Fig. 8a). In contrast, the SPION-PNIPAM01-Dox signal in late endosomes was rather stable between 2.5 and $10 \mathrm{~h}$ (Fig. 8c). On the other hand, colocalization of Dox with Rab5 continued at $10 \mathrm{~h}$ for SPION-PNIPAM02-Dox particles. These nanoparticles seemed to be stalling in early endosomes longer and reaching maximum Rab9 colocalization at $10 \mathrm{~h}$. Hence, these particles were transferred to more acidic late endosomes at later time points (Fig. 8b and d). This may also indicate a slower release of Dox from SPION-PNIPAM02-Dox and hence slower escape of Dox from the early endosome. These findings indicate that the polymer molecular weight of the organic corona could play a significant role in the endosomal transit of the nanoparticles.

\section{Conclusion}

In conclusion, the growth of thermo-responsive PNIPAM using the "grafting from" approach via ATRP from the surface of superparamagnetic iron oxide nanoparticles was successfully demonstrated. Attachment of the ATRP initiator to the surface of coated SPIONs via ligand exchange reduced core aggregation significantly and ATRP prevented cross polymerizations between the nanoparticles, and hence produced ultrasmall and stable SPION-PNIPAM nanoparticles. These nanoparticles had different polymer molecular weights controlled with ATRP, and a LCST around $38{ }^{\circ} \mathrm{C}$ which is well below the mild hyperthermia temperatures (about $42{ }^{\circ} \mathrm{C}$ ).

SPION-PNIPAM nanoparticles demonstrated great stability in water and buffer with no significant toxicity and excellent Dox-loading efficiency (96 wt\% in PBS buffer), which is highly desirable for a drug delivery vehicle. The Dox release rate from these nanoparticles is both temperature and $\mathrm{pH}$ dependent with about $90 \%$ release at $42{ }^{\circ} \mathrm{C}$ and $\mathrm{pH}$. Based on the molecular weight of PNIPAM, this release amount can be achieved in 8 or $20 \mathrm{~h}$, for the low and high molecular weight PNIPAM coating respectively, which allows an additional means to tailor the release kinetics. Most importantly at physiological $\mathrm{pH}$ and temperature Dox release is below $20 \%$ in $24 \mathrm{~h}$. This is the first demonstration of dually or even triply responsive drug release from pure PNIPAM-coated nanoparticles in the literature. Such a combination of temperature and $\mathrm{pH}$ is crucial to reduce side effects of the drug, keeping Dox entrapped under physiological conditions but effectively releasing it at the site of interest, such as endosomes ( $\mathrm{pH}$ 5.0-6.5) or lysosomes ( $\mathrm{pH}$ 4.5-5.0). Temperatures around $42{ }^{\circ} \mathrm{C}$ can usually be achieved via hyperthermia, heating the nanoparticles above the LCST of the PNIPAM coating, hence promoting the Dox release. This property will be exploited in further studies.

Toxicity was studied in a very comprehensive way and confirmed no cytotoxicity for the nanoparticles and effective apoptosis and DNA damage with the delivered Dox in the in vitro studies. The molecular weight of NIPAM not only affected the Dox loading and release rate but also influenced the endosomal escape and time to reach the nuclei which is faster with a lower molecular weight.

The superparamagnetic nature of SPION-PNIMAM was exploited for contrast generation in MRI, as well. These particles generated typical dark contrast indicating potential as T2 agents. This MR imaging modality combined with the dually responsive controlled drug release behavior makes these SPION-PNIPAM nanoparticles valuable theranostic candidates.

\section{Conflicts of interest}

The authors declare no competing financial interests.

\section{Acknowledgements}

The authors would like to thank TUBITAK $110 \mathrm{T116}$ for the funding and the scholarship of Yasemin Yar and TUBITAKBIDEB 2211-A for the scholarship of Yunus Akkoc. The authors would like to thank Isaac Imanez and Francois Rossi at ERC-Ispra and Prof. Mehmet Ali Gulgun at Sabanci University for the TEM analysis.

\section{References}

1 H. Mok and M. Zhang, Expert Opin. Drug Delivery, 2013, 10, 73-87.

2 K. Rouhollah, M. Pelin, Y. Serap, U. Gozde and G. Ufuk, J. Pharm. Sci., 2013, 102, 1825-1835.

3 A. S. Wadajkar, J. U. Menon, T. Kadapure, R. T. Tran, J. Yang and K. T. Nguyen, Recent Pat. Biomed. Eng., 2013, 6, 47.

4 W.-F. Ma, K.-Y. Wu, J. Tang, D. Li, C. Wei, J. Guo, S.-L. Wang and C.-C. Wang, J. Mater. Chem., 2012, 22, 15206-15214.

5 C. Sun, J. S. Lee and M. Zhang, Adv. Drug Delivery Rev., 2008, 60, 1252-1265.

6 H. Jeon, J. Kim, Y. M. Lee, J. Kim, H. W. Choi, J. Lee, H. Park, Y. Kang, I.-S. Kim and B.-H. Lee, J. Controlled Release, 2016, 231, 68-76.

7 M. Peller, L. Willerding, S. Limmer, M. Hossann, O. Dietrich, M. Ingrisch, R. Sroka and L. H. Lindner, J. Controlled Release, 2016, 237, 138-146.

8 C. Wang, S. Ravi, G. V. Martinez, V. Chinnasamy, P. Raulji, M. Howell, Y. Davis, J. Mallela, M. S. Seehra and S. Mohapatra, J. Controlled Release, 2012, 163, 82-92.

9 J. Beik, Z. Abed, F. S. Ghoreishi, S. Hosseini-Nami, S. Mehrzadi, A. Shakeri-Zadeh and S. K. Kamrava, J. Controlled Release, 2016, 235, 205-221.

10 F. M. Kievit and M. Zhang, Acc. Chem. Res., 2011, 44, 853-862.

11 C. Kojima, K. Yoshimura, A. Harada, Y. Sakanishi and K. Kono, J. Polym. Sci., Part A: Polym. Chem., 2010, 48, 4047-4054.

12 W. Li, D. Wu, A. D. Schlüter and A. Zhang, J. Polym. Sci., Part A: Polym. Chem., 2009, 47, 6630-6640.

13 F. Liu and M. W. Urban, Prog. Polym. Sci., 2010, 35, 3-23. 
14 G. Pasparakis and M. Vamvakaki, Polym. Chem., 2011, 2, 1234-1248.

15 K. B. Doorty, T. A. Golubeva, A. V. Gorelov, Y. A. Rochev, L. T. Allen, K. A. Dawson, W. M. Gallagher and A. K. Keenan, Cardiovasc. Pathol., 2003, 12, 105-110.

16 K. Shimizu, H. Fujita and E. Nagamori, Biotechnol. Bioeng., 2010, 106, 303-310.

17 R. A. Stile and K. E. Healy, Biomacromolecules, 2001, 2, 185-194.

18 B. R. Twaites, C. de las Heras Alarcón, M. Lavigne, A. Saulnier, S. S. Pennadam, D. Cunliffe, D. C. Górecki and C. Alexander, J. Controlled Release, 2005, 108, 472-483.

19 J. Chen, Y. Gao, Z. Xu, G. Wu, Y. Chen and C. Zhu, Anal. Chim. Acta, 2006, 577, 77-84.

20 M. A. Ward and T. K. Georgiou, Polymers, 2011, 3, 1215-1242.

21 A. Akbarzadeh, M. Samiei, S. W. Joo, M. Anzaby, Y. Hanifehpour, H. T. Nasrabadi and S. Davaran, J. Nanobiotechnol., 2012, 10, 46.

22 J. Zhang and R. Misra, Acta Biomater., 2007, 3, 838-850.

23 A. Hervault and N. T. K. Thanh, Nanoscale, 2014, 6, 11553-11573.

24 M. Urano, Int. J. Hyperthermia, 1999, 15, 79-107.

25 R. Gui, Y. Wang and J. Sun, Colloids Surf., B, 2014, 113, 1-9.

26 D. Habibi, S. Kaamyabi and M. M. Amini, Appl. Surf. Sci., 2014, 320, 301-308.

27 T. Fan, M. Li, X. Wu, M. Li and Y. Wu, Colloids Surf., B, 2011, 88, 593-600.

28 K. Ohno, C. Mori, T. Akashi, S. Yoshida, Y. Tago, Y. Tsujii and Y. Tabata, Biomacromolecules, 2013, 14, 3453-3462.

29 H. Arami, A. Khandhar, D. Liggitt and K. M. Krishnan, Chem. Soc. Rev., 2015, 44, 8576-8607.

30 S.-W. Kim and D. Khang, Int. J. Nanomed., 2015, 10, 3989.

31 J. T. Rademacher, M. Baum, M. E. Pallack, W. J. Brittain and W. J. Simonsick, Macromolecules, 2000, 33, 284-288.

32 D. Xiao and M. J. Wirth, Macromolecules, 2002, 35, 2919-2925.

33 X. Wu, X. He, L. Zhong, S. Lin, D. Wang, X. Zhu and D. Yan, J. Mater. Chem., 2011, 21, 13611-13620.
34 E. Eyiler and K. B. Walters, Colloids Surf., A, 2014, 444, 321-325.

35 G. Korkmaz, K. A. Tekirdag, D. G. Ozturk, A. Kosar, O. U. Sezerman and D. Gozuacik, PLoS One, 2013, 8, e82556.

36 Y.-W. Eom, M. A. Kim, S. S. Park, M. J. Goo, H. J. Kwon, S. Sohn, W.-H. Kim, G. Yoon and K. S. Choi, Oncogene, 2005, 24, 4765-4777.

37 E. Kneller and F. Luborsky, J. Appl. Phys., 1963, 34, 656-658.

38 G. H. Gao, G. H. Im, M. S. Kim, J. W. Lee, J. Yang, H. Jeon, J. H. Lee and D. S. Lee, Small, 2010, 6, 1201-1204.

39 F. Ye, Å. Barrefelt, H. Asem, M. Abedi-Valugerdi, I. El-Serafi, M. Saghafian, K. Abu-Salah, S. Alrokayan, M. Muhammed and M. Hassan, Biomaterials, 2014, 35, 3885-3894.

40 S. Purushotham, P. Chang, H. Rumpel, I. Kee, R. Ng, P. Chow, C. Tan and R. Ramanujan, Nanotechnology, 2009, 20, 305101.

41 M. Rahimi, A. Wadajkar, K. Subramanian, M. Yousef, W. Cui, J.-T. Hsieh and K. T. Nguyen, Nanomedicine, 2010, 6, 672-680.

42 E. P. Rogakou, D. R. Pilch, A. H. Orr, V. S. Ivanova and W. M. Bonner, J. Biol. Chem., 1998, 273, 5858-5868.

43 E. P. Rogakou, W. Nieves-Neira, C. Boon, Y. Pommier and W. M. Bonner, J. Biol. Chem., 2000, 275, 9390-9395.

44 N. Taneja, M. Davis, J. S. Choy, M. A. Beckett, R. Singh, S. J. Kron and R. R. Weichselbaum, J. Biol. Chem., 2004, 279, 2273-2280.

45 A. Ivashkevich, C. E. Redon, A. J. Nakamura, R. F. Martin and O. A. Martin, Cancer Lett., 2012, 327, 123-133.

46 B. Sui, H. Xu, J. Jin, J. Gou, J. Liu, X. Tang, Y. Zhang, J. Xu, H. Zhang and X. Jin, Molecules, 2014, 19, 11915-11932.

47 X. Yang, J. J. Grailer, I. J. Rowland, A. Javadi, S. A. Hurley, D. A. Steeber and S. Gong, Biomaterials, 2010, 31, 9065-9073.

48 T. J. Yacoub, A. S. Reddy and I. Szleifer, Biophys. J., 2011, 101, 378-385.

49 K. Weis, Cell, 2003, 112, 441-451.

50 S. Kornfeld and I. Mellman, Annu. Rev. Cell Biol., 1989, 5, 483-525.

51 I. Mellman, J. Exp. Biol., 1992, 39. 